\title{
The evolutionism of the Parables ${ }^{\dagger}$
}

\author{
Francisc Gafton ${ }^{1 \star}$, Adina Chirilă ${ }^{2}$ \\ ${ }^{1}$ Faculty of Letters, "Alexandru Ioan Cuza" University, Bd. Carol I 11, 700506 Iași, Romania \\ ${ }^{2}$ Faculty of Letters, History and Theology, West Univerity, Bd. Vasile Pârvan 4, 300223 Timişoara, Romania
}

\begin{abstract}
Article info
History:

Received September 10, 2019

Accepted October 1, 2019

Published November 7, 2019

Key words:

evolutionism

bible text

genotype

phenotype

ideology

Abstract

Revisiting the parables in the New Testament, the authors of the present paper find elements that support the interpretation of these stories in the light of evolutionism-a concept of considerable depth. If perceived as a whole, and aside of any mystical reflection, the parables affirm the existence of a system generating and governing all the principles and entities, which, consequently, share its nature, namely its order, its equilibrium, and its vitality.

Entities have the vital force generated by an entelehic genetic datum, fundamentally positive, but which can be maintained, developed and evolved as such only as a result of the epigenetic becoming, in that direction.

Naturally for him though, the religious human being subordinates the genetic datum, the epigenetic acquired, as well as the instruments of behavioural and ideological nature to spirit and the fulfilment of God's will.
\end{abstract}

I. SENTENCES AND PARABLES. The analysis of the acknowledged Gospel-textus receptus-shows that some of its components are able to prove certain general mentality and conception regarding the daily linguistic and cogitational deeds, human behaviour as well as the human ethical and moral principles. The richest ones in this regard are the hortatory component-paremiological statements and parabolic stories - and the ethological one, where concrete facts are often discursively clarified. Even if each of them does not contain all the elements of the others, the corpus thus constituted is coherent, systemic and relevant to the teaching of the Gospel, and between the emitter's words and facts, there is a harmonious relation, the facts not contradicting the wording, and the wording not being contradictory to the facts.

The paremiological statements group mainly in the sermon on the mountain $(M t, 5 ; 6 ; 7 ; L c, 6,20-$ 49), which tells generalities, principles, but also sufficient specific elements in a mentality and behavioral point of view, regarding various particular or general situations. Synthesizing part of the traditional and generally human wisdom, they anticipate the explicit teachings and the direct facts that will follow. Due to the aphoristic feature of the paremiological statements, the interpretive and twisting possibilities they have, may be considerable.

\footnotetext{
${ }^{\dagger}$ The texts we consider are part of the class of texts, which - in particular-are usually viewed from a supposed mystical dimension, their hermeneutics being thus oriented, even when it claims itself purely exegetical. In such cases, it is difficult to prove what and how much it belongs to the author, what and how much to the interpreter. Moreover, from such a position it is often decreed that everything that does not take into account a mystical, symbolic, allegorical etc. content and does not concern the construction of the text and of the discourse as one fully controlled by the author and somehow guided, is inadequate to that type of text and it is therefore erroneous. This method does not only legitimize a perspective, but it also generates with its supporters, the prejudice of the impossibility of any other perspective, feeding their claim that another perspective is wrong. Of course, that, often, the associations are operated by the interpreter's mind so exercised and it cannot be demonstratedscientifically, not rhetorically-that the meanings are extracted from the text, and not induced by the interpreter and established by the theological and religious tradition. Not taking into account any mystical dimension and avoiding interpretations, our analysis tries to listen and observe only what the text conveys by itself and compare its conceptual essence with that of other texts. The references and quotations refer to the latest full version of the Bible, in Romanian, published in Iași, in 2013, and belong to Alois Bulai and Eduard Patrașcu.

^Email address: algafton@gmail.com.
} 
Perhaps the oldest and certainly the handiest human approach of acquiring some knowledge of the world derives from an attribute of the biologically organized living matter, that is the abilities to perceive sensations meant to impress and to stock and process them. Practicing these abilities-especially after storage, comparison and symbolization of large amounts of sensorial information-lead to the occurrence of a complex bio-social epiphenomenon, namely the peculiarity of differently interpreting the same information and operating forecasts based on the stock of information-existing one or imaginative product, through correlations. Thus, the first step towards the thorough and accurate knowledge of reality is loaded remains subject to sensoriality and imagination, so that even when knowledge seems to get close to the ontic reality, the grounds remain those given by the first results of the imaginative processing of the sensation.

Therefore, it is often impossible to show beyond any ambiguity what exactly did the forger or compiler of boutades understand or mean. He may start from a mere impression or from the direct or not direct observation of a very specific and particular situation-both the impression and the observation being generated by an acute or vague state, or by any particularism-but he may also start from a generalizing and abstracting synthesis of some classes of concepts and acts. Of course, in this context it becomes difficult to find out what, how much and how did the contributor understand and want to convey, but also what, how much and how, and why the shares of the boutade's elements have changed and what and how much everyone understands, by virtue of their knowledge, their mental and cultural experience, of their capabilities and associative determinations, of their existential data in general. Eventually, the contact of the boutade with reality - the former variable as intensity and extension, and the latter, various, nuanced, protean-may induce new changes, ameliorative ones or on the contrary, suitable or not, anyway some deviations from the origin thought.

All these mechanisms of interpretation and forming are active wherever the communication of a reflection outcome is involved. Between the paremiological statements and parables, the former ones are by far the most exposed to (re)semantisations, their somehow enigmatic nature, deliberately encrypted and with tendencies towards generalization and towards universal validity implicitly favouring this process.

On the other hand, parables are a way of transmitting a message constructed as such that by presenting simple and known actions, presented by suggestive analogies and metaphors-the emitter refers to conceptions and thoughts that are accessible to the receiver and which have intrinsic validity. In addition, the first one can easily make "fine adjustments", by clearly explaining-by paraphrase or discourse focused exclusively on the message itself. Moreover, the structure and the content of the parables clearly show the illustrative-persuasive intention of the one who builds and propagates them. Thus, almost every parable presents well-highlighted and simple characters and events, that stand out by few and easy-to-identify features. The one- or bi-dimensional character of the event and of the protagonists does not allow too much speculation, all elements of parabola construction stimulating its reception in the direction of the narrator's intention. With the concern of eliminating the interpretative slag, it is attentive to the correct orientation of the receiver, protecting it from the erroneous interpretation of the discursive elements or from its engagement on directions inconsistent with the signification of the intention of the discourse. In a way, parables are the discursive equivalents of the living example, generated by the execution of an action, possibly explained.

II.1. Evolutionism is not a datable conception, ideas that may be considered evolutionist inherently appearing, from the earliest eras in History. However, evolutionism itself has evolved, knowing various avatars, enlargements, restrictions, developments, shades-normal, aberrant or inhibitory. But what matters here is whether the perspective that generates, animates, nourishes or just accompanies a conception may or may not be considered evolutionary. Therefore, considering that, in contrast with sentences, parables do not stimulate twisted interpretation, but it provides objectivity with more possibilities, and considering that, in fact, they imagine mentality and behavioural models, we will hereunder examine parables seeking to find out whether they validate the predicate in the title or not, which claims that they 
would have an evolutionist vein.

II.2. The System. A fundamental requirement to understand and design the reality from the evolutionary perspective refers to its systemic feature. Operating in an environment with inter-determination relationships with different shares, the open and dynamic system is a complex and coherent structural and functional entity, with spatial and temporal existence, and among whose elements there are and operate necessary and efficient relationships, continuously adjustable according to external requirements and internal needs, all of which work together to make it both homeostatic and evolutionary.

A fundamental and consistent constituent of the philosophy of parables is the highlight and tracking of systemicity, naturally involving the respect for the systemic structure and the essential valuation of order and hierarchy - on the criteria of identity and stability of the genetic datum, of the functional efficiency of the epigenetic structure and of following the will of the God. Thus, there appear the unequivocal statements in favour of the undistracted compliance with continuity and hierarchy, as in the parable of the faithful servant $(M t, 24,45-51 ; L c, 12,41-48)^{1}$, and against breaking the continuity of principle, of the non-anointment, of the imposture, as it is exemplarily illustrated by the parable of the murderer tenants $(M t, 21,33-46 ; M c, 12,1-12 ; L c, 20,9-19)^{2}$.

For the same reason, one argues in the direction of not preventing the natural course-which is towards development and which does not mean the mere preservation, but the evolutionary struggle-and the valorisation of the genetic datum by constituting a suitable epigenetic framework and by following ideologically nourished actions and compliant to the divine will, as in the parable of the talents $(M t, 25$, $14-30 ; L c, 19,11-27)^{3}$.

Therefore, the homeostatic maintenance of the status quo is not a form of inertia and immutability, but a stage in the game between the identity-giving stability and the adaptive evolution, the preservation being necessary for the maturing consolidation of a state, and the change occurring naturally as a result of natural quantitative and qualitative accumulations, being an incipient part of the evolutionary process.

II.3. The GenOtYPE. Once established the crucial importance of systemicity, this becomes the foundation and the existential modality of some constitutive processes, of development and fundamental evolutionary. The starting point of the genetic datum theme in the philosophy of the Parables is illustrated by that of the mustard seed and of the dough $(M t, 13,31-35 ; M c, 3,30-34 ; L c, 13,18-21)$ and that of the seed that grows $(M c, 4,26-29)$. Here it is asserted the vital force of matter and the entelehic feature of the genome. But after the disclosure of the fullness and the illimitation of the power of creation, the concrete act follows, with the sower at its beginning. He spreads, apparently randomly, a set of seeds havingtheoretically-the same potential and similar features. The action itself and the environmental conditions triggers different effects, the seeds falling in different places, from some totally unsuitable for fertilization, to ones optimum to the process, the results being consistent to the various contexts, from the lack of any chance of sprouting to plenary fruitfulness $(M t, 13,3-23 ; M c, 4,3-20 ; L c, 8,4-15)$. From here already emerges the teaching that the mere existence of a potential cannot constitute a value in itself, what matters

\footnotetext{
${ }^{1}$ In which it is shown that the servant must strictly and promptly obey his master's orders and with all consciousnesseses undertake those attributes and behaviours that made him worthy to receive the role he has in his master's plans and in the society. This should lead him to reject the attributes and behaviours he would tend to as a being devoid of the awareness of its role and which would bring him in contradiction with the quality of element (this one, at its level, a system) of a system. Therefore, under $L c, 17,7-10$, there appears a teaching such as: "Is it necessary to thank the servant for obeying the orders? Likewise, when you do all the things you are ordered to, say, «we are useless servants, we did what we owed to do".

${ }^{2}$ Which tells about some tenants of a vineyard, who disobeyed the vine master's messengers of and killed his heir-all of them sent to bring to the master of the vine the fruits of his property-and whose foreseeable punishment is death, the vine was to be entrusted to other tenants, able to comply with the established order and to accurately understand its true role.

${ }^{3}$ Which tells about a master who has entrusted his servants with different amounts (apparently randomly, possibly depending on their potential or capabilities). On their return, they returned the capital to him, together with the profits obtained, except for one, who preferred to bury his talent, so as to make sure that he was able return the amount without loss. This angered the master, who said he did not accept to have no profit, so he exiled the server and distributed the amount of the one who had managed his amount in the most efficient way.
} 
being the successful consequence of the good update of the potential, with its entailing effects. This is because not everything what could exist will exist, and nothing of what exists does necessarily exist-as the parable of the corn cockle shows $(M t, 13,24-30)^{4}$, of the sower and the elements of some more.

II.4. The Phenot ype. Although the genotypic datum is indispensable-its fulfilment through existence implicitly ascertaining its quality-it is only the first step. By fulfilling the call of the deity to come into existence, the individual enters a world whose elements are factors he interacts with, all the factors and all the processes he encounters acting upon him selectively, on mainly functional criteria. For this reason, at this level, the fundamental necessity is the accommodation to reality, by word, thought and deed-an act that may be accomplished by obeying the divine commandments.

Probably the philosophy regarding the relationship between the genotypic datum and the phenotypic acquired, between potency and act, reaches its climax in the parable of Lazarus the poor and of the unnamed rich $(L c, 16,19-31)$, where there appear two individuals at extremes: one lives in abundance, the other one in major shortcomings. Without any explicit motivation, just to build up a teaching, we are told that after death the former one reaches a place of maximum suffering, and the latter of maximum bliss. In addition, more than in the earthly life, the boundary between the two worlds is impossible to cross. Understanding that he could no longer do anything for himself, the rich man prays Abraham to send someone to warn his living brothers to save them from such a fate. Exemplary his deep philosophy, (but also through intransigence and through the secondary substrate ${ }^{5}$ ) the answer ${ }^{6}$ shows that the only real and effective way to avoid eternal suffering or to obtain eternal bliss is by following the laws written in the holy books. Any other encouragement or help would be useless as he who does not observe the laws by himself does not possess the capacity to understand the necessity of observing them either, or the one of obeying them as due $\mathrm{e}^{7}$. Although this parable shows the importance of the ideological factor-we are going to analyse-it would have been more appropriate to be evoked here, as it clearly bespoken the formative processes that precede the ideological component.

Given the divine source of the datum, as well as its great stability, it constitutes in itself a direction towards the Good, being somehow implicit landmark and guide. At first, man only has to follow his nature (created and imprinted by divinity). Running this process makes the good instincts prevail, so nothing else is needed, nothing more to be offered, everything else coming from itself. As with any given, anything that does not flow organically form the nature of the given cannot occur. This would be the cause why he who does not perceive and does not act by the means he has, cannot be directed or bestowed by foreign action: everyone is exactly as he is and nobody changes as a result of an external impulse. As a matter of fact, this would contravene both the coherence of the system and the selection which filters the good from the bad and favours the development and the evolution of the good from and through good.

Even so, nevertheless, the relationship between the genotypic datum and the phenotypic acquirement

\footnotetext{
${ }^{4}$ Which tells about a farmer who sowed good seed, but at night, an enemy sprouted corn cockle in the sowing. His servants are instructed to pluck it, but not immediately, only at harvest time, when the naturally different nature of the two plants would render easy the separation of wheat from haze; the former will be placed in the barn, the latter will be spouted in the fire. Due to the harmful nature of the corn cockle (on the quality of the harvest, not on the wheat plant development process), its fate is established and sealed ahead, its life until then not being and unable to be relevant, redeeming or anyway, and the apparent postponement of the fulfilment of its destiny being nothing more than a simple technique to facilitate the extirpation of evil without harming the good.

${ }^{5}$ Perhaps of all the places in the New Testament (too numerous) in which those somehow endowed are simply marked because, by valorising their talent, they exist by having, and the those lacking it are in favour only because they exist by laying op, this one is the most contradictory in relation to the precepts of love and forgiveness, both from God to man and from man to man, as well as with the one that urges man to action, according to the divine commandments.

6"They have Moses and the Prophets; to listen to them! (...) If they do not listen to Moses and the Prophets, even if someone raised from the dead, they would not be convinced!".

${ }^{7}$ This thought of maximum strength strongly recalls the reply from $J u d, 6,31$ : "Do you want to defend Baal? Or do you want to save him? (...) If he is God, let him defend himself, because they have torn down his altar!” It essentialises a conception as evolutionist and selectionist as possible, which characterizes the entire history of the Jewish nation, constantly self-submissive to the refineries and adaptive selection, constantly evolving in this way.
} 
is more complex as it seems, the former not being a passive frame, but a set of "materials" able of generating structures and having action-generating features. Man's task and duty is to valuably activate the first oneby thought, word and deed, consistent with the divine will explained through the teachings of authority. But this is done by unimpededly going on unimpeded paths - from the environmental inadequacy, passing through their own distress and reaching the action of the social and mentality forces. The weaknesses or the will of a badly constructed man places him outside the frameworks set by divinity, which is the source of the differentiated treatments - unless divinity disposes otherwise.

Although both the genotype and the phenotype have their own capacities of directed self-drive, the environmental factors have forces able to divert the two. Therefore, the genotype constantly needs to be updated by a well-established phenotype, and the phenotype constantly needs to be maintained by the divine learning - the only one that can keep him on the right path-always nourished by the unbroken faith-the only landmark easily accessible to man. Although crucial, the genetical datum needs not to be preyed upon by the changes generated by the defectively oriented exercise and to be fulfilled by the fruitful and efficient exercise, produced in conformity with the conjunction between itself and a good phenotype. Equally crucial, the epigenetic acquired needs not to update all its possible attributes, but only those concordant with the conjunction between a well-constituted self and the divine teaching.

II.5. IDEOLOGY. The importance of the ideological factor is so great as it could not escape anticipation. The genetic datum and the epigenetic acquired have functional efficiency as their existential purpose, which must be conform to the divine will. The biological and genetic datum is not sufficient for life to unfold according to the God's will. This is not because it would be imperfect or incomplete, but because the material being must activate it in an environment, by congruent thoughts, words and deeds, then to practice and develop it in the right direction. In its turn, this environment is itself an outcome that is constituted, oriented, developed and determined by previous thoughts, words and deeds, which has generated an ideologically imprinted mindset. In this way it acquires the epigenetic dimension, this one not sufficient through itself either. Equipped with conscience and some free will, the human being must demonstrate to the deity that the datum was correctly oriented, that the talent was well and efficiently used, that the being is capable of its own, consciously oriented and deliberate struggles, choosing and thoroughly following the path marked by divinity, possessing the strength to keep it despite the powerful disturbing factors.

This fullness can only be reached by adopting the fulfilling component, the ideological one-the fundamental, the dominant and the matrix dimension, which gets to weigh the hardest and be livingly present in any form of religious existence. It is the only one which can support by itself thoughts, words and deeds which are concordant among them and with the divine teaching. The interrelation between the three components grants the being stability and identity, dynamics and adaptation, continuity of journey. As it genuinely combines rigidity with elasticity, by their functioning, all three components are able to modulate, to recover, to somehow convert the human being, but also to guide it by testing it, and to help it guide itself (to the point where, even proposing the exercise of self-analysis, the human being is no longer able to discern between orientation and his/her own will).

In this context, starting with the moment of temptation $(M t, 4,1-11 ; L c, 4,1-13)$, it is clearly observed the strong affirmation of the power of the spirit over matter, of the imperious necessity to have unwavering faith. From the utmost trust in the divinity $(M t, 6,25-34 ; 6,19-21 ; L c, 12,22-33)$ the force of prayer and the force of faith flow $(M t, 17,19-20 ; 21,18-22 ; M c, 9,28-29 ; 11,12-14 ; 20-25$; $L c, 9,40-42 ; 17,5-6)$, which have the power even to redeem, however weak faith and prayer may be in themselves $(M c, 9,24)$.

II.6. The Supremacy OF IDEOlogy. The centrality of the ethnic dimension is related to respect for systemicity and the strength of the datum, which is why, under special conditions, the ideological factor may exceed the genetic one. The biblical text abounds in situations where the antithesis between what is specific to a community and what is foreign to it. The brother or the fellow man is always the blood one, 
the community being fundamental with this. Therefore, the fellow man must be forgiven "until seventy times seven" $(M t, 18,21-22)$, the tolerance towards it being almost unlimited: "If your brother is wrong against you, go and reprimand him only between four eyes! (...) If he does not listen to you, take one or two with you «so that any decision may be based on the statement of two or three witnesses »! If he refuses to listen to them as well, tell the Church! And if he also refuses to obey the Church, let him be a pagan and a publican to you!" $(M t, 18,15-17 ; L c, 17,3-4)^{8}$. The last sequence shows that in a system where the genetic fellow man is infinitely more important than the other one, it is vital for the maintenance of the system also to consider both the stimulation of the mindset and of the beneficial behaviours and the elimination of the harmful ones, even if (in fact, especially if) it is about the genetic fellow man, as in $D t, 19,15-19$ (which culminates in the sequence: "Destroy the evil in your midst"). This is because every form of degradation of the community ideology of renunciation to it is equivalent with the loss of identity, while the mere genetic identity must be confirmed by the ideological one, that is, the spirit prevails over matter.

If there is no genetic identity, the epigenetic and the ideological one is appreciated. Therefore, although in the New Testament the ethnic foreigners continue to be left outside the community and treated differently, elements of some tolerance appear towards those of them who have attributes which indicate the compliance with the behavioural and especially the ideological norms of the community they are not part of. It is recommended for them to be treated as affinal relatives. Naturally, the genetic fellow man is "closer" than the non-genetic one, but cases like that of the Roman centurion $(M t, 8,10-13)$, of the Cananæan $(M t, 15,21-28)$, of the Syrophœnician's endevilded daughter $(M c, 7,24-30)^{9}$ shows that, in fact, in the profound reality, the ideology can transcend the genotypic community, and the treatmentdifferentiated at the beginning according to the genetic and cultural belonging - may be modified when the epigenetic and behavioural factors change the importance of belonging or point to another one, at a higher level.

Although such cases cause astonishment, although they hardly gain recognition, and though they face increased demands when requesting acceptance, by virtue of the same respect for the system and for the ideology - thus reinforcing those affirmed by the teachings -, the stranger gets to be verbally recognized as an affinal relative and used as a provocative example ${ }^{10}$.

Eventually, the same is the context that explains the production of a repeated discourse of legitimacy $(M t$, 7,24-27; Mc, 13, 28-32; Lc, 6, 47-49; In , 10, 1-18; In , 15, 1-17), the double measure from the sabbatical happening, in which the disciples did not formally follow the rules of Saturday, breaking and eating spikes $(M t, 12,1-8)$, as well as derogations regarding the exaggerated behaviours, but favourable or pleasing to Jesus (for example, $M c, 14,3-9 ; L c, 7,36-50$, and in many other places, not so obvious, but equally

\footnotetext{
${ }^{8} L c, 17,3-4$ refuses to foresee for the final situation. In fact, the Greek Luke is more careful under this aspect, seeming to perceive things differently, as seen in the parable of the friend $(L c, 11,5-8)$, where it is shown that the friend in need should be helped irrespective of the context, he asks for help in.

For details, see the parable of the unjust judge $(L c, 18,1-8)$, which tells about the fact that a judge lacking the fear of God and the shame of people-but to whom a widow constantly demanded for justice-listens to her request because of his inability to bear the tireless insistence of the woman.

${ }^{9}$ Attenuated in $L c, 17,3$; in $M t$, merged with 18, 21-22.

In all these parables, those foreigners benefit from a treatment that is not conform to the common one for foreigners, a fact that occurs by virtue of the facts and conceptions that they do and state them in a clear and decisive way.

${ }^{10}$ Moreover, the rhetorical component is so powerful that it could be said with equal justification that the praise given to strangers does not mean their acceptance, but only hortatorily provokes the brothers, as in the somewhat extreme case of family redefinition, from this perspective $(M t, 12,48-50)$. Thus, the parable of the Samaritan $(L c, 10,29-35)$ does not explicitly show that ideology and deed go before genetics, and it is rather a parable which extracts its efficiency from leading to the extreme and reducing to the absurdity a constructed situation to very vividly imagine what Jesus wanted to be treated by his people with the utmost seriousness.

The parable of the tribute $(M t, 17,24-27)$ only apparently enters this category. There we have a trivial example of strategy by which the weak is urged to submit to the secular power.
} 
unequivocal), eccentricities $(M t, 8,22)^{11}$, sophistic motivations $(M t, 9,14$ and so on) or abuses-even if understandable from a cultural and temporal perspective, however, fundamentally, abuses $(M t, 8,14-$ $15)^{12}$ - healings based only on the assumption that thus one of Isaiah's prophecy is fulfilled $(\mathrm{Mt}, 8,16-$ 17).

II.7. The SElection. The comparison of the wide range of the genetic datum and of the existence of several possibilities of updating it, with the narrowness of the path agreed by divinity, shows that the mere existence of several genetic and epigenetic possibilities, then of the ability of self-guide (in order to activate the genetic datum and the constitution of the epigenetic acquired) does not mean that any possibility and orientation is good and to be followed. The fact is announced even from the sermon on the mountain, where it is said-by way of many forms, but also explicitly-that the gate to a life according to God's will, which leads to salvation, is tight by itself, and the simple acceptance unconfirmed and unsuccessful through consistent deeds, leads to perdition $(M t, 7,13-14 ; 21-27$ and $L c, 13,22-32)$. From here it is understood that the human being has to make efforts in the direction of its setting on the good and narrow path, agreed by the deity. But man does not always make this effort. An incorrectly updated genetic datum, a defectively functionalized epigenetic acquired and especially an ideological disorientation given by the misunderstanding and not assuming the meaning of the human being in the world leads to thoughts, words and deeds contrary to the expectations of the God. And when the tree does not give its natural fruit ( $M t$, $12,33-35 ; L c, 6,43-45)^{13}$, the God acts selectively, in order to obtain the necessary segregation between good and evil $(M t, 13,47-50)^{14}$.

The parable of the lost sheep $(M t, 18,12-14 ; L c, 15,4-7)^{15}$ and that of the prodigal son $(L c, 15$, $11-32)^{16}$ do not contradict the necessity of selecting and eliminating the evil, do not support the tolerance towards deviation, but strictly refer to the recovery of the detained good, to the restoration of the state of completeness. Even if it refers only to the "lost sheep of the house of Israel" - which must ultimately be fully rendered to Yahweh -, or it may also include others, these sequences emphasize the imperative of maintaining whole or of rebuilding the community endowment, the perspective being both of the divine master (who set the imperative), as well as of the possessor (the temporary administrator), who must obey the commandment. As for the

\footnotetext{
${ }^{11}$ Where there appears a piece of advice such as, "Follow me, and let the dead bury their dead!" addressed to someone whose father had just died and whose funeral-according to the customs, the rules of common sense and hygiene (the Eastern religions excel in) - the son was to take care of.

${ }^{12}$ Where Peter's mother-in-law-who was lying sick and in a feverish condition-is touched, her fever diminishes, after which she gets up and serves Jesus and Peter. Although the first act the woman does after healing is to serve the two, it is difficult to really know if the point of healing was the concern for the woman's health, the satisfaction of a friend (Peter) or the immediate profit.

${ }^{13}$ Where there are statements that show that the good generates good and the bad - bad, the products being coherent to the producer. Naturally in and for the Semitic mentality, here it is also shown that language is relevant to the nature and the real state of man, who, therefore, will be judged according to his words; consequently, there should be overlap and congruity between words and deeds.

${ }^{14}$ Which tells about the selection - which will be undivertedly made-between the good and the bad, between those who lived in compliance, respectively, in contradiction with the divine commandments.

${ }^{15}$ Which tells about the fact that the keeper of many sheep (one hundred), losing one of them, will look for it, and when he finds it, he will rejoice it more than the non-wandering of the other 99. (In $L c$ it is exaggerated the letting into lurch of the other 99, not specified in $M t$. As a matter of fact, $M t$ is attentive to the possessor's state of heart, which becomes pleasant compared to the previous one.)

${ }^{16}$ Which tells about a parent who had two sons. The younger one asked his father for his part of the fortune and went away with it, where he wasted it, leading an unruly life. After living a time under the miserable conditions his own reckless phenotype placed him in, unable to bear more, he came back to his parental home. Gladly, his father gave him the most expensive clothes and ordered a feast, treating his son not according to his deeds, but according to the possibilities of the father and the birth of the son. In the meantime, the eldest son-who had remained with his father and who had been devoted to the interests of the head of the family - was in the field, toiling. On his return, angry at the way his brother was welcomed, he refused to enter the house, perceiving everything as great injustice. But his father teaches him that nothing would change as far as he was concerned, but he, as a parent was happy for the physical recovery of his lost son.
} 
object possessed, it does not change its status either given or assumed by conscious acts, the communication not referring to it, but only using it, for it does not necessarily matter.

A perverted genotype, in conjunction with a tailor-made phenotype, are reflected by a behaviour that does not comply with the reasons for bringing the individual into existence and by an ideology that is not compliant with the one given and required by the deity. This leads to the distraction of the order, an obvious fact in the parable of the merciless servant, the one capable of taking advantage of undeserved benefits and skilful in obtaining the debt exemption $(M t, 18,23-35)^{17}$. But in this parable, it is not the servant's behaviour that gives the central parable, but the master's behaviour. Although it has a genotype and a phenotype that seem good, his tolerance towards the servant which shows him to have a weak ideological component, through its irreparable consequences, his action being more severe than the servant's entire action in the world. Thus, although it shows the tendency to do its duty, the first order being in the direction of the compliance with the laws imposed by the proper functioning of the system, he will miss fulfilling the role of agent of selection and will wander practicing the anti-selection. Even if subsequently he will correct himself and will apply the selection, the correction cannot be complete as the server had generated an evil that, if the selection had been applied from the beginning, it would have not been made and which, therefore, had unforeseen consequences in the initial plan. They should be corrected by modifying the plan, which implies effects on other elements (people) of the plan.

It would be wrong to believe that this is a case of applying the anti-selection to the situation and to the man who do not match. In fact, the act does not stem from necessities generated by applying the principles and by observing the functioning of the established system in the image of those principles, but out of the mere mercy generated by the psychic weakness or by a harmful social or ideological calculation. The fact shows that tolerance lacking systemic grounds leads to evil, anti-selection demanding anti-selection, in a spiral of self-destruction.

Although it was viewed almost exclusively in its dimension of eliminatory sieve, in its full reality, selection is a mechanism and a process that stimulates and favours life, in the fullness of its attributes of an integral, harmonious, functional, efficient and evolutionary system ${ }^{18}$. What can irreparably destroy life is anti-selection because it either stimulates directions calculated by man (a being to which knowledge is inaccessible in a way of the structural and functional wholeness it acts upon as such ${ }^{19}$ ), either as attributing an undue merit incites to the development and evolution of the states of non-movement (retaining the talent) or of the ways to obtain such merits (the skilful servant in obtaining its undeserved forgiveness of debt), that is, the anti-systemic paradigms, and never to the beneficial adaptation of life and real evolution.

II.8. Aberration. The deviation from the genotype and the failure to enact it in accordance with its own nature is a misstep that must be corrected or removed - as divinity disposes. As what appears outside the datum is needless-as shown in $M t, 15,13$ : "Any plant that my heavenly Father has not planted will be plucked from its roots", because the garden belongs to the gardener, he arranges everything according to his will (also see $M t, 21,18-19$ ) - equally harmful is the deviation from the rules established by the God-as understood from the parable of the feast of wedding $(M t, 22,1-14 ; L c, 14,15-24)^{20}$.

\footnotetext{
${ }^{17}$ Which tells about a servant who owed the king a huge sum, which he could not pay. In danger of being sold as a slave together with his family, he asks for mercy, promising to pay the debt. Nevertheless, in his turn, he was not merciful to the one who owed him, but sent him to prison. Upon finding out, the king withdrew his grace and applied the punishment he should have applied from the very beginning, thus somehow restoring natural order and getting close to the compliance with the terms of natural laws governing.

${ }^{18}$ In a system in which the genetic and ideological fellow man is infinitely more important than the otherness, naturally the maintenance of the system by stimulating the mentality and the beneficial behaviours and the elimination of the harmful ones refers to the genetic fellow man, as in $D t, 19,15-19$ (culminating in the sequence: "Destroy the evil in your midst"). This is because any form of degradation of the community ideology or even of renouncing it is equivalent to the loss of identity and annihilation.

${ }^{19}$ The ideology to acquire and follow is only the divine one. It is given, and man only has to discover it in all its permissive fullness, not to interpret it, reconstruct it or adapt it, and not to build another one to apply to a World he does not know.

${ }^{20}$ Which tells about a king who made wedding invitations, but no one honoured them. After killing those who disregarded
} 
II.9. Punishment. The action of the Law in the direction of the Good and Balance called Justice may be obstructed by the reckless and unguided action of people, generating Godlessness, Evil and Imbalance called Injustice. The thought, word and deed according to the divine teaching are rewarded, and the noncompliant ones are corrected by punishment. Reward and punishment are motor and educational tools, with an exclusive pedagogical-guiding characteristic ${ }^{21}$. They belong to the God, as shows the parable of the vine workers $(M t, 20,1-16)^{22}$.

Nevertheless, from a human perspective, the genetic and epigenetic mechanisms are much too little known to people, sometimes contradicting human logics-mostly due to the mere ignorance of those mechanisms. Therefore, from a human perspective, the God may sometimes seem to have a intriguing behaviour. In fact, the one who builds the game, the players and the rules may make any kind of changes, apparently without connection with the thought, the deed and the way the players play. But this is so because - at some point and in a certain meaning - all of them are guilty, anyone can pay, just to serve as a warning and an exemplum to all ("Neither he or his parents have sinned, but it is so to have the works of God revealed in him", In, 9, 3; see also $L c, 13,1-9)^{23}$.

It is significant that, unlike John the Baptist, who urges to repentance in the twelfth hour ${ }^{24}$, Jesus announces the judgment and declares that he came to fulfil the Law. He does not carry out a persuasive act and does not negotiate for the purpose of mending, but he simply warns, he does not winnow possibilities, but the digs consequences into stone $(M t, 10,34-39 ; L c, 12,49-53$; $14,26-27)^{25}$.

III. Conclusions. Given the foregoing we believe that it is quite clear that the parables affirm the existence of a system generating all principles and entities, which impose on the latter an existence and functioning according to its image, that is, under order and balance. As systems and as elements of some systems, entities have the vital force generated by an entelehic genetic datum, fundamentally positive, but which can be maintained, developed and evolved as such only as a result of the epigenetic becoming.

For the religious man, the resultant called spirit holds the predominance of the primordiality and of the absolute principality, the great modelling and guiding factor being the unalterable faith $(\mathrm{Mt}, 7,24-$ 27 ), in order to fulfil the purpose for which there exists the genetic datum, the epigenetic acquired, as well as the instruments of behavioural and ideological nature. This faith may represent its main guide, the religious man striving to fulfil the will of the God and placing itself mainly or exclusively in the ideological area.

the invitation, the king asks his servants to invite anyone they meet on the street, without distinction. Entering the dining room, however, he punishes a guest who came in an improper outfit.

${ }^{21} \mathrm{As}$ in $D t, 19,20$ : "Those who remain hear and fear to do such an evil thing in your midst!".

${ }^{22}$ Which tells about a vineyard owner who engages daily workers, successively, at different times over the course of a day, but pays them with the same amount-as actually agreed. This fact, however, has as a consequence the revolt of the workers who had worked since the first hours, who issue judgments from a narrow human perspective.

${ }^{23}$ Which tells about the non-differentiation between some who have been treated badly and others who were left in peace: "It seems to you that these Galileans were more sinners than all the other Galileans because they suffered this? I tell you, by no means! If you do not convert yourselves, all of you will perish in the same way", and where the parable of the fruitless fig is stated, in which - as relevant as possible both the perspective and the human mentality-the slave (man) pleads for leniency.

Here it is observed that neither the individual as such matters nor the exclusively preventive character of punishment does. The god is not interested in revenge (but of course he does not leave it in the hand of the feebleness human being) or in punishment as a punitive act, but by the example thus given to those who have chances of fulfilling his will.

${ }^{24}$ In front of him, devoid of a militant's nature, Iona-about whom it is explicitly stated that he had been sent by divinityhad made somewhat mechanistic-empirical reasoning, manifesting itself as a kind of mechanism of adjustment of divine action.

${ }^{25}$ In which there appear statements like: "I came not to bring peace, but a sword!", "He who does not take up his cross and follows me is not worthy of me. He who cares about their life will lose it, and he who loses his life for me will regain it", "Fire I came to set on earth and what other do I want than to have it lit! Do you think I came to bring peace on earth? Not at all, I tell you, but to split it", "If anyone comes to me and does not hate his father, mother, woman, brothers, sisters, but even his own life, cannot be my disciple". 